\title{
Acariasis en erizo pigmeo africano (Atelerix albiventris) en cautiverio en Paraguay
}

\section{Acariasis in African pygmy hedgehog (Atelerix albiventris) in captivity in Paraguay}

Joerg Richard Vetter Hiebert¹, María Gabriela De Vera Fernández², Diego Augusto Dacak Aguilera ${ }^{3}$

1 Universidad Nacional de Asunción, Facultad de Ciencias Veterinarias, Departamento de Recursos Faunísticos y Medio Natural. San Lorenzo, Paraguay. 2 Profesional Independiente. Dermatología Veterinaria. Asunción, Paraguay. ${ }^{3}$ Clínica Veterinaria Diego Dacak. Asunción, Paraguay. Autor de correspondencia: jvetter@vet.una.py

Resumen: La acariasis es un problema común en el erizo pigmeo africano (Atelerix albiventris). Caparinia trípilis es responsable por la infestación por ácaros más frecuente. La presencia de sarna es común y puede causar coinfecciones bacterianas. El trabajo describe dos casos de sarna por Caparinia trípilis en el erizo pigmeo africano, un macho y una hembra, adultos, diagnosticados mediante evaluación clínica y microscópica de lesiones obtenidas por raspado. Los pacientes acudieron a consulta debido a que presentaban prurito intenso y caída excesiva de púas. El tratamiento consistió en la aplicación de ivermectina a dosis de $0,4 \mathrm{mg} / \mathrm{kg}$ por vía subcutánea. Se realizó realizado el control clínico de los pacientes a los 14 días, con la re-aplicación de la ivermectina, a la misma dosis.

Al control se pudo observar una mejoría clínica completa. La presencia de Caparinia trípilis en erizos ha sido descrita ampliamente en los Estados Unidos de Norte América, Nueva Zelanda, y varios países de Europa, pero aún se requiere información de Centro y Sudamérica, y se informa aquí su presencia en Paraguay.

Palabras clave: Erizo pigmeo africano, Atelerix albiventris, Caparinia trípilis, ivermectina, Paraguay.

Abstract: Acariasis is a common problem in African pygmy hedgehogs (Atelerix albiventris), being Caparinia tripilis the main reported infestation. The presence of mites is common and can cause co-infections with bacteria. This work describes two cases of Caparinia tripilis mites in an adult African Pygmy Hedgehogs, a male and a female, diagnosed through clinical and 
microscopic evaluation of material obtained by scraping. The patients went to the practice as showed intense pruritus and excessive spine loss. The treatment consisted in subcutaneous ivermectin application at a dose of 0.4 $\mathrm{mg} / \mathrm{kg}$. A control was made after 14 days, with another ivermectin application, at the same dose. A complete clinical improvement was observed during the control. The presence of Caparinia tripilis in hedgehogs has been described extensively in the United States, New Zealand, and many countries in Europe, but there is still information missing about Central and South America, making this work a report of its presence in Paraguay.

Keywords: African Pygmy Hedgehog, Four-toed Hedgehog, Atelerix albiventris, Caparinia tripilis, Ivermectin, Paraguay.

\section{INTRODUCCIÓN}

El erizo pigmeo africano (Atelerix albiventris) se distribuye naturalmente a través de África ecuatorial y central. Es bastante diferente del erizo europeo, que es mayor y marrón, y no hiberna. Las hembras pesan 250-400 gramos y los machos 500-600 gramos (adultos no obesos) ${ }^{(1)}$.

Según la Unión Internacional por la Conservación de la Naturaleza (IUCN), la especie está clasificada como "Preocupación menor", en vista de su amplia distribución; y probablemente esté presente en varias áreas protegidas y tenga una tolerancia a la modificación de hábitat(2).

Esta especie se ha convertido en una mascota muy popular en la última década $\mathrm{y}$, por ende, su presencia en los consultorios ha aumentado. Su susceptibilidad a enfermedades como la fiebre aftosa, ha significado que sus importaciones desde África estén severamente restringidas o prohibidas, lo cual puede tener consecuencias como la reducción del banco genético y el posible aumento de desórdenes genéticos, asociados a la endogamia ${ }^{(3)}$.

Los pelos de los erizos se modifican en púas que cubren la superficie dorsal. Hay un área estrecha sin espinas que corre desde la corona de la cabeza rostro caudalmente durante unos $2 \mathrm{~cm}$., aproximadamente. La piel de la espalda tiene una epidermis delgada que recubre una capa fibrosa dérmica gruesa, y debajo una capa de tejido adiposo y subcutáneo. Aunque dicha área a menudo sea utilizada para la administración de líquidos, la vascularización es pobre. Las glándulas sudoríparas y las glándulas sebáceas están presentes en las regiones provistas de púas y en las plantas de los pies. Los erizos recién nacidos lucen un pelaje de espinas suaves y blancas que se endurecen en unas pocas horas. Un segundo crecimiento de espinas más oscuras y duras emerge 2 días después del nacimiento. En esta especie, las púas se reemplazan a las 4, 6, 9 y 12 semanas $^{(3)}$.

La acariasis es un problema común de los erizos pigmeos africanos cautivos, al igual que las subsiguientes infecciones profundas y superficiales por 
dermatofitos(1). Típicamente, los géneros de ácaros que infectan erizos son Caparinia, Chorioptes y Notoedres $(4,5)$; también se mencionan entre los ácaros de importancia a los Sarcoptes, Otodectes, como así también las especies Demodex erinacei y Trombicula autumnalis( ${ }^{(6)}$. En cautiverio, los animales afectados a menudo presentan escamas, costras y pérdida de púas. El diagnóstico de los ácaros se puede realizar con un raspado de piel(4).

Los ácaros pertenecientes al género Caparinia (Canestrini, 1894) perteneciente a la familia Psoroptidae, incluye varias especies, entre las cuales $C$. tripilis y C. erinacei (Fain, 1962) son las más conocidas(7). La especie C. tripilis (Figura 1) se identifica como la más frecuente entre los erizos criados en cautiverio ${ }^{(7)}$. Se menciona una prevalencia de entre $40-100 \%$ en acariosis producida por $C$. tripilis, lo que sugiere que este ácaro puede ser considerado un ectoparásito normal en la piel de los erizos, sin producir signología clínica ${ }^{(8)}$.

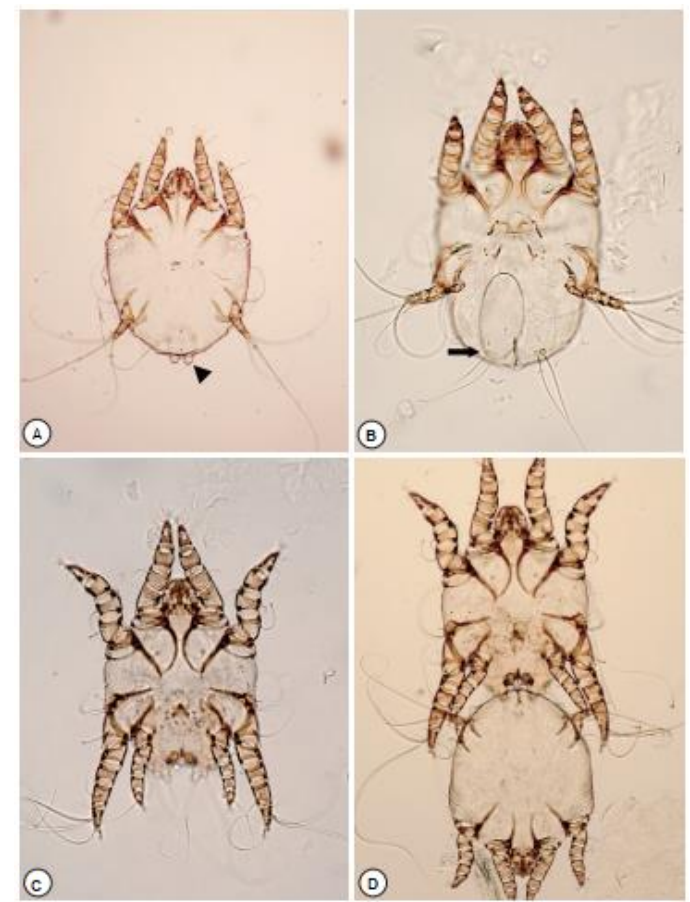

Figura 1. Caparinia tripilis. (A) Vista dorsal de una hembra pubescente. (B) Vista ventral de una hembra ovígera (hembra adulta) que contiene un huevo. (C) Vista ventral de un macho adulto. (D) Una pareja en acople: macho adulto arriba y hembra pubescente abajo. (Fotos: Kim et al, 2012) ${ }^{(7)}$.

El objetivo de este trabajo es reportar la presencia de Caparinia trípilis en Paraguay, sus manifestaciones clínicas y un tratamiento efectivo. 


\section{DESCRIPCIÓN DE CASOS}

Se presentan al consultorio dos ejemplares de erizo pigmeo africano (Atelerix albiventris). El primero, una hembra adulta, con $300 \mathrm{~g}$ de peso corporal. La propietaria manifiesta que al animal se le caen mucho las púas (Figura 2) y presenta excesivo prurito. El segundo, un macho de 9 meses de edad, con 220 g de peso corporal. La propietaria manifiesta que desde hace aproximadamente 30 días se le caen las púas (Figura 3), y hace aproximadamente 7 días fue reduciendo paulatinamente el consumo de alimentos hasta la anorexia.

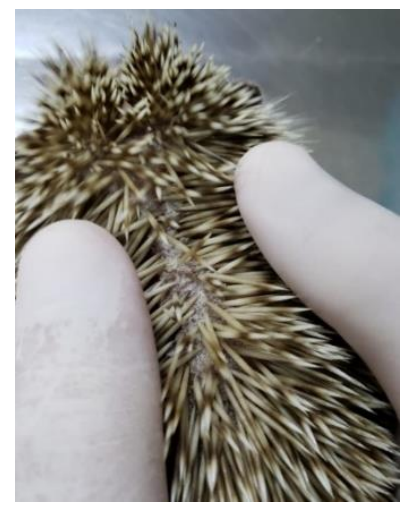

Figura 2: Descamación del manto en el paciente. (Foto: Gabriela De Vera).

A la inspección clínica de los animales se observa descamación del manto (Figura 2) con desprendimiento notorio de las púas (Figura 3). No se percibe otra particularidad. 
Rev. Soc. cient. Parag. 2020;25(1):86-93

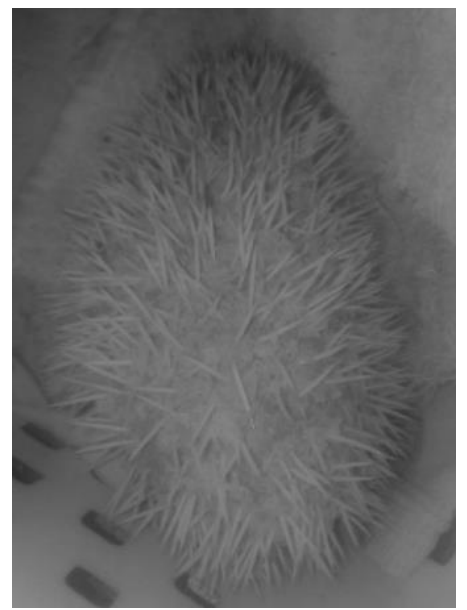

Figura 3: Extenso desprendimiento de púas. (Foto: J. Richard Vetter).

Se realizó el examen de piel y púas mediante el raspado de las mismas. A la observación microscópica, con el objetivo de 10x se detectó primero la presencia de huevos (Figura 4) y luego la presencia de ácaros (Figuras 5, 6). El ácaro detectado es de cuerpo redondeado, aplastado ventralmente y convexo dorsalmente. Uno de los ácaros fue medido, y presenta un ancho de $172 \mu \mathrm{m}$ y $304,24 \mu \mathrm{m}$ de largo. Por sus características morfológicas, los ácaros coinciden con Caparinia tripilis (Figurat 1).

Figura 4: Huevo de ácaro hallado. (Foto: Gabriela De Vera). 
Rev. Soc. cient. Parag. 2020;25(1):86-93

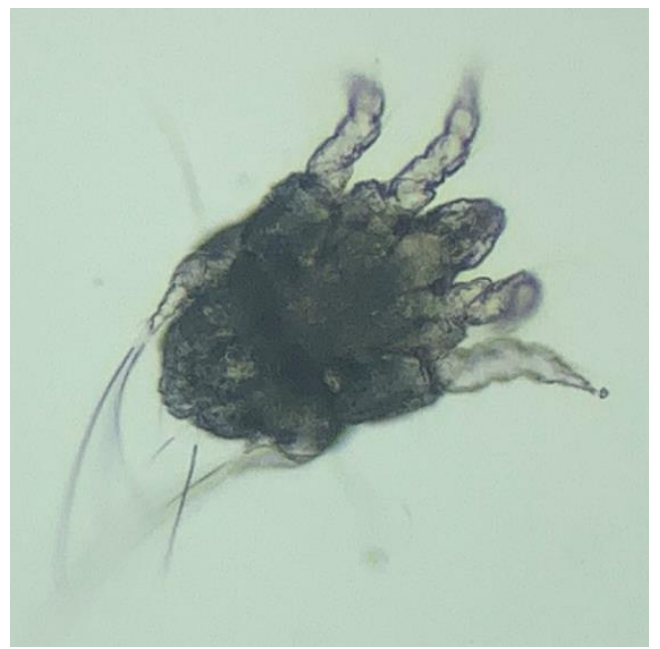

Figura 5: Ácaro hallado, vista dorsal. (Foto: Diego Dacak).

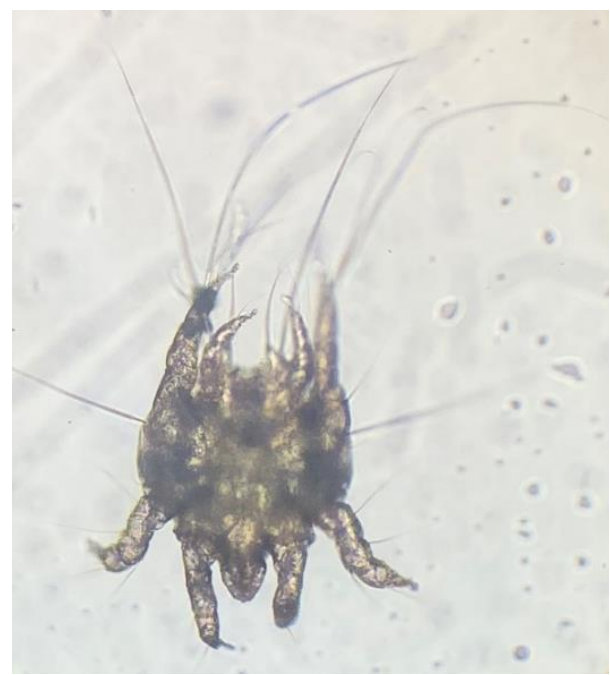

Figura 6: Ácaro hallado, vista ventral. (Foto: Diego Dacak).

\section{TRATAMIENTO}

Se realizó la aplicación subcutánea de Ivermectina a dosis de 0,4mg/kg, con una re-aplicación a los 14 días ${ }^{(9)}$. A las 48 horas de la aplicación, las propietarias manifiestan que ya no se presentan signos de comezón, y el ejemplar macho se alimenta normalmente. A la inspección luego de 14 días 
los animales presentaron una mejoría clínica completa. Las propietarias manifestaron que las mascotas no se rascan, ni se presenta caída de púas, o presencia de costras en la piel.

\section{CONCLUSIÓN}

Este trabajo reporta la presencia de Caparinia tripilis en erizo pigmeo africano en Paraguay, coincidiendo con las matrices existentes para su identificación(7).

La acariasis puede presentarse en una co-infección bacteriana, pero en este caso no se observaron signos de infección bacteriana. Se puede considerar al estrés, la falta de higiene o una disfunción inmunológica como predisponentes para una infestación por ácaros; sin embargo, se ha considerado que Caparinia sp. podría ser un habitante normal en la piel de los erizos ${ }^{(10)}$.

La presencia de ácaros en erizos domésticos es común en los Estados Unidos, Europa y Nueva Zelanda ${ }^{(1,10)}$, pero aún falta información al respecto en gran parte de Centro y Sudamérica.

El tratamiento único con ivermectina es eficaz en erizos con ácaros del género Caparinia sp. en estado inicial. En casos más avanzados se deberá evaluar la combinación con otras drogas. Se menciona la utilización de Fluralaner en erizo pigmeo africano como tratamiento contra la sarna ${ }^{(11)}$ pero se requieren mayores estudios para determinar su eficacia.

\section{AGRADECIMIENTOS}

Prof. Dra. Leila Maidana, por las correcciones y recomendaciones. Clínica Veterinaria Fauna Town, de Agrofield S.R.L., por ofrecer las condiciones para desempeñar libre y correctamente nuestra profesión. A las propietarias, quienes acompañaron el tratamiento, demostraron interés en el seguimiento, reportaron periódicamente la evolución y apoyaron la publicación de los casos.

\section{REFERENCIAS BIBLIOGRÁFICAS}

1. Johnson-Delaney CA. Otros pequeños mamíferos. En: Meredith A, Redrobe S, editores. Manual de Animales Exóticos. 4⿳亠丷厂 ed. Barcelona: BSAVA; 2012. p. 141-163.

2. Cassola F. Atelerix albiventris (errata version published in 2017). The IUCN Red List of Threatened Species 2016: e.T40602A115174097. Disponible en: http://dx.doi.org/10.2305/IUCN.UK.20163.RLTS.T40602A22324217.en. 
3. Jepson L. Exotic animal medicine: a quick reference guide. $2^{\underline{a}}$ ed. St. Louis: Elsevier; 2016.

4. Perry SM, Sander SK, Mitchell MA. Integumentary System. En: Mitchell MA, Tully TN, editores. Current Therapy in exotic pet practice. St. Louis: Elsevier; 2015. p. 17-75.

5. Riera A, Cabrero M. Manejo y tratamiento de los animales exóticos. Madrid: Mayo; 2008.

6. Paterson S. Skin Diseases of Exotic Pets. Oxford: Blackwell; 2006.

7. Kim DH, Oh DS, Ahn KS, Shin SS. An outbreak of Caparinia tripilis in a Colony of African Pygmy Hedgehogs (Atelerix albiventris) from Korea. Korean J Parasitol. 2012;50(2):151-156.

8. Iacob O, Iftinca A. The dermatitis by Caparinia tripilis and Microsporum, in African pygmy hedgehog (Atelerix albiventris) in Romania - first repor. Rev. Bras. Parasitol. Vet. 2018;27(04):584-588.

9. Helmer PJ, Carpenter JW. Hedgehogs. En: Carpenter JW, editor. Exotic animal formulary. 5a ed. St. Louis: Elsevier; 2018. p. 634-656.

10. Moreira A, Troyo A, Calderón-Arguedas O. First report of acariasis by Caparinia tripilis in African hedgehogs (Atelerix albiventris), in Costa Rica. Rev. Bras. Parasitol. Vet. 2013;22(01):155-158.

11. Romero C, Sheinberg Waisburd G, Pineda J, Heredia R, Yarto E, Cordero A. Fluralaner as a single dose oral treatment for Caparinia tripilis in a pygmy African hedgehog. Veterinary Dermatology. 2017;28(06):622e152. 